\title{
How can Urban Planners Address Emerging Zoonoses? A Scoping Review of Recommended Interventions
}

Vignesh Murugesan*

\begin{tabular}{|c|c|}
\hline ARTICLE INFO & A B S T R A C T \\
\hline $\begin{array}{l}\text { Received: June } 16, \\
2020 .\end{array}$ & $\begin{array}{l}\text { Emerging zoonotic diseases (EZD) like Severe Acute } \\
\text { Respiratory Syndrome (SARS), COVID-19, and Ebola } \\
\text { have highlighted the need for incorporating emerging }\end{array}$ \\
\hline $\begin{array}{l}\text { Received in revised } \\
\text { form: October 17, } 2020 .\end{array}$ & $\begin{array}{l}\text { zoonoses considerations in urban planning practice. To } \\
\text { mainstream EZD in urban planning, this scoping review } \\
\text { collates recommendations from across disciplines to }\end{array}$ \\
\hline $\begin{array}{l}\text { Accepted: October 30, } \\
2020 .\end{array}$ & $\begin{array}{l}\text { provide directions to city planners and policymakers. A } \\
\text { search of published literature examining the relationship } \\
\text { between EZD and urban planning or policymaking was }\end{array}$ \\
\hline Published online: & conducted in February 2020 using PubMed, Web of \\
\hline November 15,2020 & $\begin{array}{l}\text { Science, and Scopus. Thirty-six articles were identified by } \\
\text { the review process and the research examining the } \\
\text { relationship between urban planning and EZD was found to } \\
\text { be limited but expanding. In identified articles, } \\
\text { recommendations for planners were found to address } \\
\text { various areas and aspects of planning like inter-disciplinary } \\
\text { collaboration, social justice, built environment, climate } \\
\text { change adaptation, urbanization, sanitation, green space } \\
\text { and economic planning. The applicability of these } \\
\text { recommendations to global north and south cities is also } \\
\text { discussed. }\end{array}$ \\
\hline
\end{tabular}

Key words: cities - socio- infectious disease - planning practice - review

To cite this article: Murugesa,V., (2020). How can Urban Planners Address Emerging Zoonoses? A Scoping Review of Recommended InterventionsUrbana, XXI. Retrieved from http://www.urbanauapp.org/ https://doi.org/10.47785/urbana.4.2020

\footnotetext{
* MES Planning Candidate, School of Planning. Faculty of Environment University of Waterloo
} vmuruges@uwaterloo.ca 


\section{Background}

\subsection{Introduction}

Since early times humans have largely strived to shape and modify their environment to reduce risks to themselves. This intent to decrease risks and increase longevity coupled with a better understanding of health risks and the microbial universe have changed how cities function and look over time (McKeown, 1971; Pijnenburg \& Leget, 2007). However, our society still faces several health risks that threaten to take lives, destroy livelihoods, and induce diplomatic and political tensions (Bloom et al., 2018). Recent outbreaks of infectious diseases like Coronavirus (COVID-19), Ebola and Severe Acute Respiratory Syndrome (SARS) have shown us how ill adapted our current global, national, and local government systems are to face these risks.

\subsection{Infectious Diseases and City Planning}

\subsubsection{Early Outbreaks and Cities}

The origin of planning is intertwined with communicable diseases. Early city planning emerged as a response to outbreaks that were mostly related to the quality of the urban environment (Kochtitzky et al., 2006). Absence of formal planning in medieval cities resulted in a number of issues like the lack of clean drinking water, accumulation of filth on the streets (due to animal dung and emptied chamber pots), crowding in small living quarters, and buildings with no windows (Ciecienzki, 2013; Evert, 2007). These characteristics of urban spaces created conditions under which communicable diseases could spread very easily.

The mid-14th century bubonic plague outbreak ravaged Europe and this was facilitated by the poor sanitary conditions of the urban areas (Gottfried, 2010). Even in the early modern period, cholera outbreak of 1848 killed about five per cent of the population in two of the very densely populated neighbourhoods in Paris (De Moncan \& Heurteux, 2002, p.10). Such infectious disease outbreaks have become less and less frequent over time because of the modern planning practices that prioritized sewer system, delivery of clean water, proper burial of the dead, stricter building and environmental norms.

\subsubsection{Modern Cities}

Medical advances in the late modern and contemporary times have made it possible to treat medieval infections and even prevent them (Ackerknecht, 2016). These advances continue to make up for poor and inefficient planning in communities across the world where sanitation and clean water is still a luxury. In addition to the medical advances, the 20th and 21 st century have changed the nature of the global economic system. The globalization has changed the characteristics of cities in several ways. This increased global movement of people, ideas, goods, services, lifestyles and capital has resulted in demographic, social, and economic transformation (Kara, 2019). The global economic transformation alongside urbanization has resulted in the rapid expansion of cities and increase of urban population both in the global north and south (Narayana, 2010). 
Many cities benefit from this globalized system; however, this comes at the cost of shared global risks. These risks can be financial, political, environmental, or health related (World Economic Forum, 2020). Very contagious diseases that would have taken several years to reach another side of the globe in middle ages can reach within days if not hours in present times. This was seen in the case of SARS as well as COVID-19, and they are characterized as emerging infectious diseases.

While technological advances like air travel network may have facilitated the transmission of these diseases, transmission of useful information and research since the onset of COVID-19 has also been facilitated by technological advances like online meeting software and knowledge sharing platforms. The ramifications and legacy of globalization has been contested in literature but the processes that give rise to and facilitate the outbreak of emerging zoonoses transcend globalization, and often come down to local level service delivery, regulations and enforcement in different jurisdictions as discussed in later sections.

\subsubsection{Emerging Zoonotic Disease}

An infectious disease is categorized as 'emerging' if it satisfies any of these three conditions: 1) it is a known disease that is rapidly increasing in incidence or geographic range in previous two decades 2) there has been an outbreak of previously unknown disease 3) a persistent infectious disease that cannot be controlled (Oaks Jr et al., 1992; van Doorn, 2013). Some examples include HIV infections, COVID-19, Lyme Disease, dengue fever and SARS.

Among the emerging infectious diseases, $73 \%$ of the infections are transmitted to humans from animals (Taylor et al., 2001). Diseases transmitted in this manner are called zoonotic diseases or zoonoses. Almost all established human pathogens have moved to humans from animals over several millennia of human evolution (Weiss, 2001; van Doorn, 2013).

Over the last century, most of the epidemics and pandemics have been identified to be zoonoses. This includes AIDS, SARS and Ebola (Morse et al., 2012). The challenge posed by the possibility of similar pandemics cannot be overstated. The ongoing COVID-19 pandemic is testament to that. The United Nations Secretary-General António Guterres recently referred to it as the biggest challenge humanity has faced since World War 2 ("Coronavirus outbreak 'greatest since WW2"', 2019).

\subsubsection{Need for Novel Interventions}

There is a need for interventions at all levels of government for preparing communities for this massive challenge. In the wake of any disease outbreak, it is the public health and medical sector that comes into focus and rightly so. But, to achieve the public health objectives and prepare the community for an emergency as well as the long run, city planning interventions are also very much required (Ahmed et al., 2019).

The first section discusses the methods used to conduct this scoping review. This includes the research questions, criteria for selecting articles, and data analysis steps. The second section outlines the trends and themes that emerged in the course of the review. The recommendations for 
planners to prevent and manage Emerging Zoonotic Diseases (EZD) from the literature are presented thematically in this section. In the third section, a general overview of the findings is provided along with recommendations for researchers and practitioners.

\section{Methods}

2.1. Research Question and Scope

This scoping review is guided by these two questions:

1. What recommendations exist in current literature for planners concerning emerging zoonoses?

2. How are they applicable to the global north and south?

The scope of the review would be peer-reviewed papers and reports from reliable organizations like United Nations from 2000 to the present. The year 2000 has been chosen because of the onset of SARS from 2002 onwards. SARS being a communicable disease that spread mostly in cities, triggered increased conversations about the role of city planning in preventing and managing infectious diseases. Taking the year 2000 as the starting point would provide a pre-SARS and post-SARS picture of the literature linking zoonoses and urban planning interventions.

\subsection{Data sources and search strategy}

The articles were sourced from Scopus, Web of Science and PubMed databases. In these databases, different combinations of search terms were used for obtaining all the relevant articles for this review. Different search terms containing key words like urban and zoonotic diseases were used to obtain relevant research articles. Some of the combinations used are as follows: i. "emerging infectious disease" AND urban* AND plann* ii. zoono* AND infectio* AND urban* AND plann*. Apart from searching databases, Google search engine was used to obtain any related articles or reports.

\subsection{Citation management}

The relevant papers obtained by searching the databases were saved in RefWorks 2.0, an online bibliography manager. RefWorks is a useful platform for sorting, reviewing, storing, and citing articles. This online platform was also used for removing duplicate references and creating bibliography in the appropriate format for this paper. It was also employed in different stages including title and abstract relevance screening and data characterization. 


\subsection{Eligibility criteria}

The articles included in the review had to satisfy all the following conditions. The articles included in this review are published between 2000 and 2020. They are peer reviewed or from other credible sources like the United Nations (UN) bodies. Importantly, these articles should offer guidelines or recommendations for urban planning practitioners or academics to integrate, better anticipate, prevent, prepare for, or manage EZD. The articles can be from any disciplinary background but had to be available in English because of linguistic limitations of the author. Articles available solely in other languages were excluded. Different types of papers like reviews, qualitative, quantitative, and mixed method studies were included.

\subsection{Title and abstract relevance screening}

Once the research articles matched the eligibility criteria, they were stored in RefWorks. Following this, individual paper titles and abstracts were read by the author to eliminate articles that were deemed irrelevant or outside the scope of this review. The established eligibility criteria were used to facilitate the screening and elimination process. As a result of this process, a final list of shortlisted articles was obtained.

\subsection{Data characterization}

The papers that were shortlisted after title and abstract relevance screening were subjected to full text review at this stage. The full texts of papers were obtained through the author's institutional library access. The established eligibility criteria were applied while reviewing full texts and papers not meeting the criteria were excluded at this stage. The criteria were easy to apply, and a final list of shortlisted papers were saved in RefWorks. The data from shortlisted papers like publication year, publication type and area of focus were compiled in a spreadsheet.

\subsection{Data summary and synthesis}

All the data was entered and stored in Microsoft Excel 2010 for coding. Different themes were identified in the papers and they were categorized and analyzed accordingly. In Excel, the descriptive graphs were generated to depict the distribution of papers across themes. 


\section{Results}

3.1.Search and selection of articles
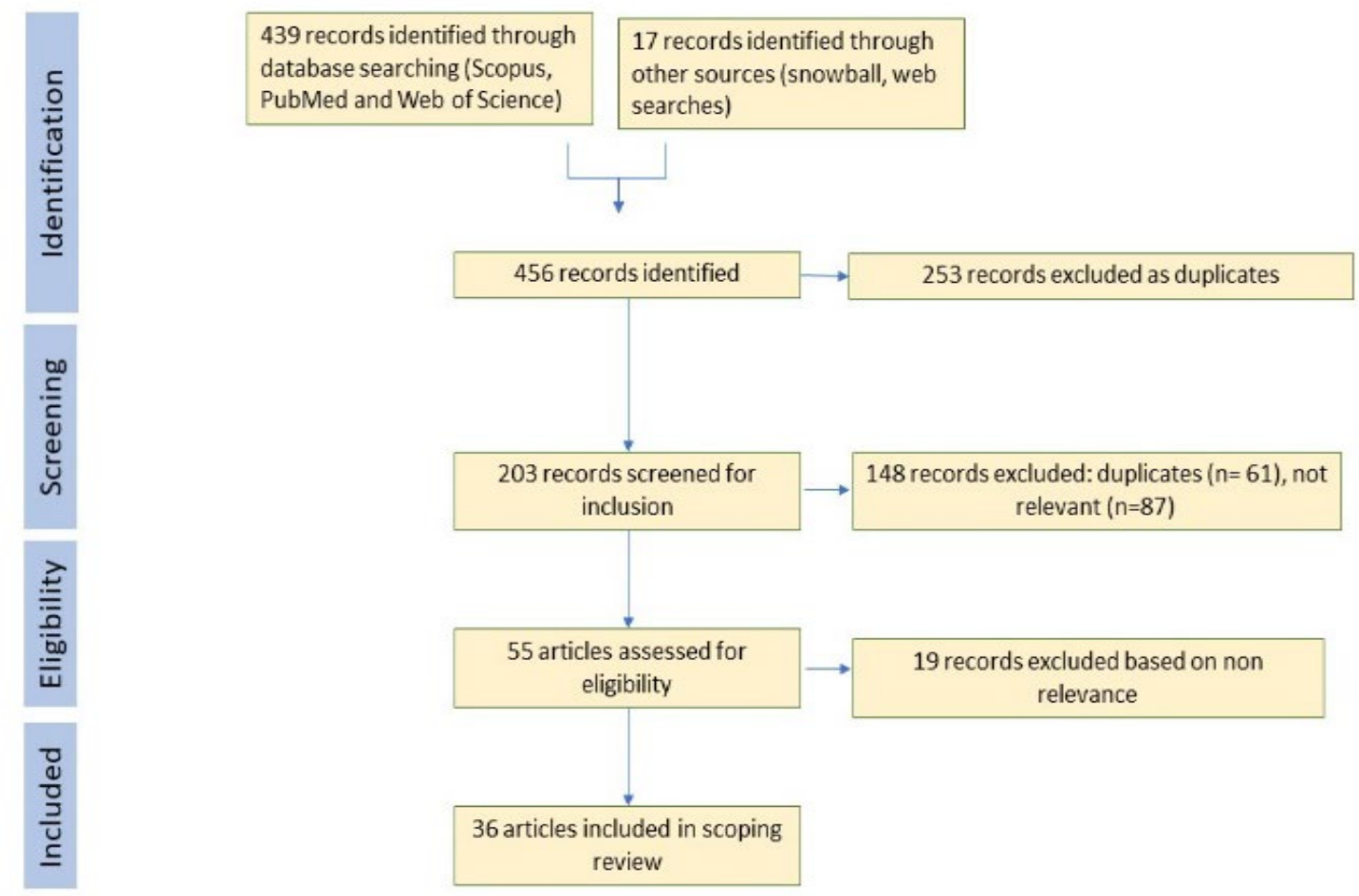

Figure 1. PRISMA flowchart of study selection process

The search for articles was conducted in February 2020. The database search yielded 439 citations while the web search yielded 17. In total, 456 citations were identified by this exercise. After this, duplicate citations were identified and removed. This yielded 203 unique records. In screening stage, it was realised that several studies that made it to title and abstract relevance screening stage focused on epidemiological and medical studies associated with diseases in urban areas. Therefore, 87 non relevant documents were identified. Additional 61 duplicates were also excluded at this stage.

Following this, the full texts of articles were reviewed with the eligibility criteria in mind. This resulted in elimination of 19 more articles. As a result, there were 36 final candidates for this scoping review at the end of selection process. 


\subsection{General Trends Observed}

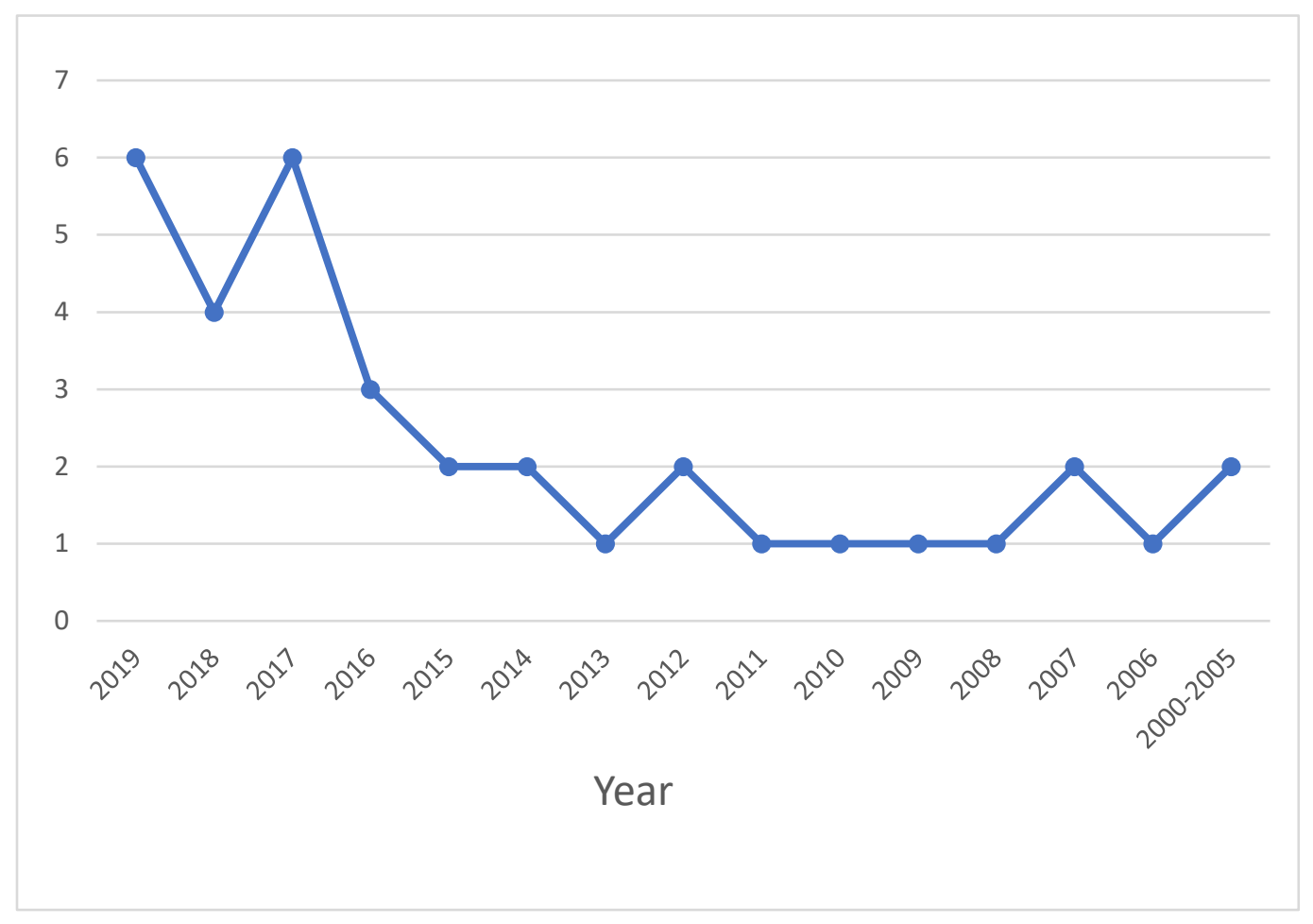

Figure 2. Number of papers over years

It was found that most of the articles that qualified for this review were published over the last five years i.e. $61.1 \%$ of the papers were published since 2015 . It was also noticeable that all the 36 selected papers were academic articles from peer reviewed journals. The recent uptick in number of articles that provide guidelines for city planning in relation to zoonoses can be attributed to the rise of 'One Health' approach that advocates for multidisciplinary problem solving.

The proportion of different kinds of studies is depicted in Figure 3 using a pie diagram. Quantitative studies were found to have higher representation in comparison to all other kinds of papers, followed by reviews. Qualitative studies only account for $17 \%$ of all papers, while only one mixed methods paper was found among the selected papers. 


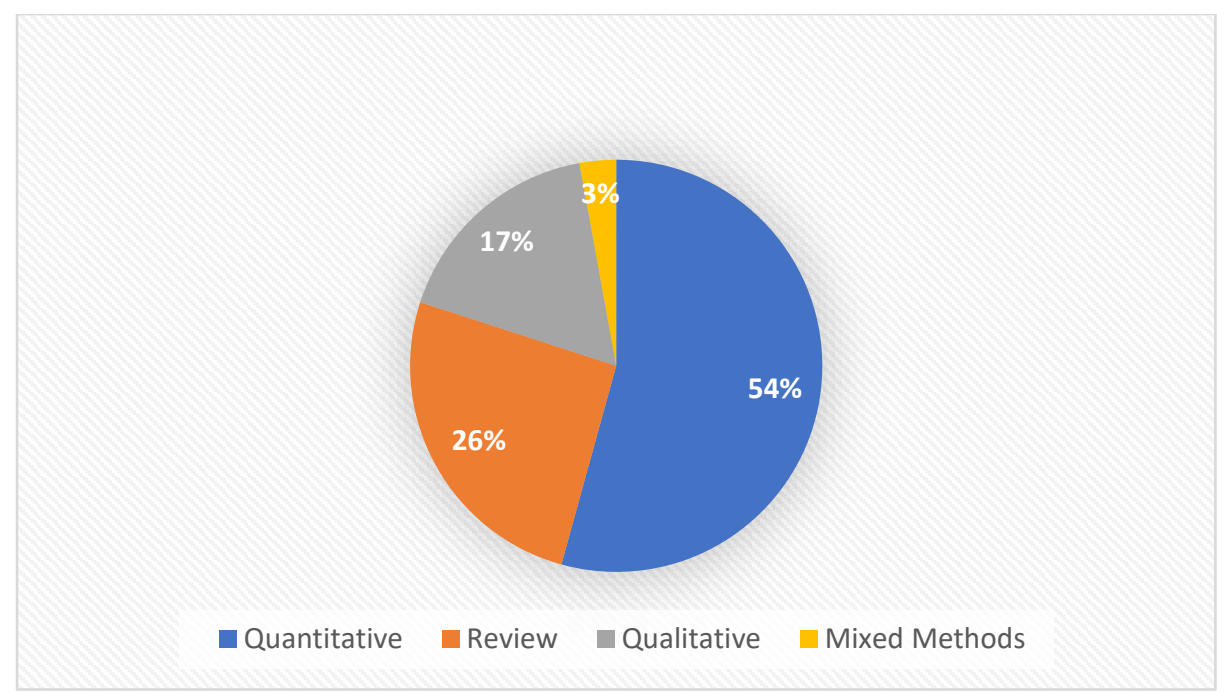

Figure 3. Proportion of different kinds of studies

It was also noticeable that SARS finds mention in one third of the papers and it was the central theme in $18.5 \%$ of the non-review papers. Other zoonotic diseases that papers focus on include Avian flu, Rabies, Plague, Dengue, Hantavirus among others. However, SARS is found to dominate the discourse in comparison to other zoonoses.

\subsection{Identified Themes}

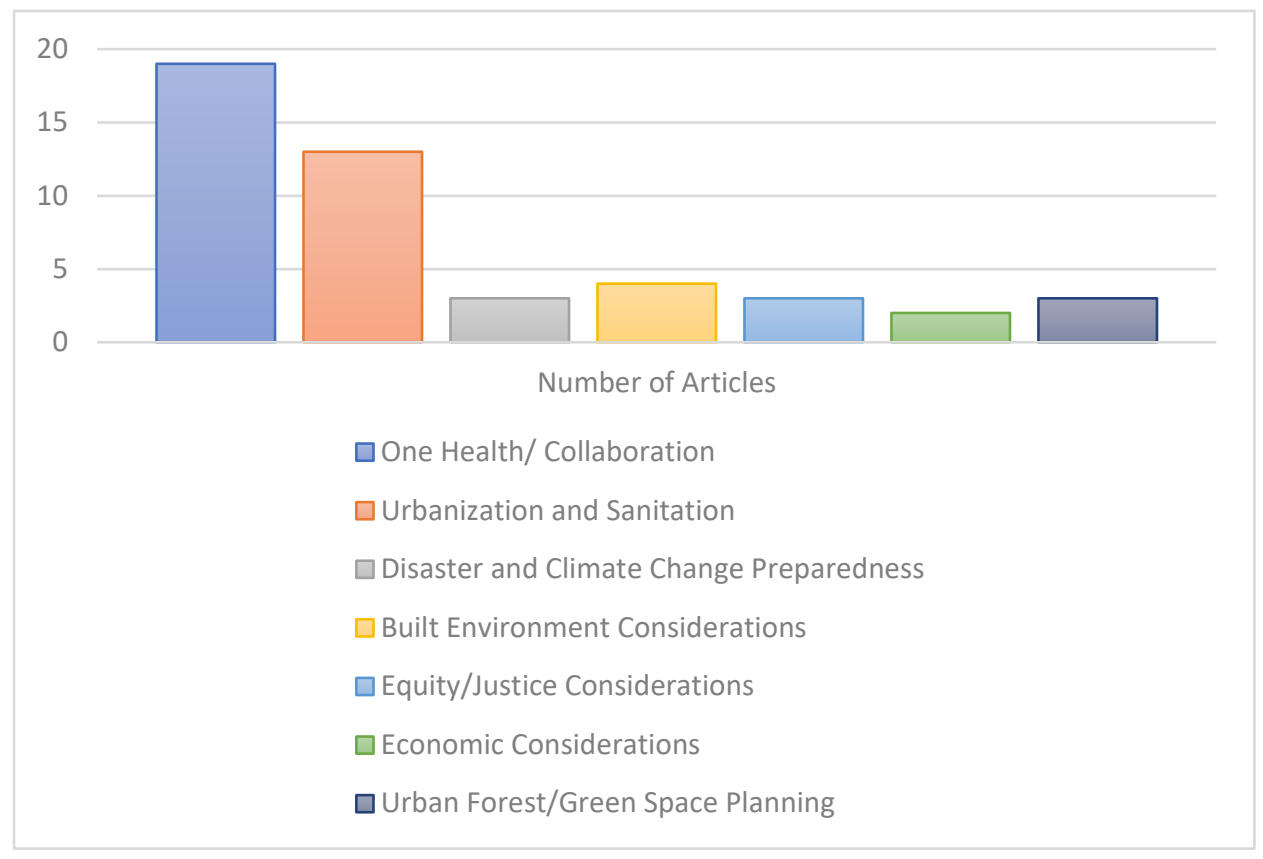

Figure 4. Themes covered in articles 
Several recommendations and guidelines for urban planning were found in the selected literature. These guidelines span over different areas of practice within planning. In many cases, individual paper provided guidelines for different areas of practice. Therefore, for the sake of representation and convenience, if a paper provided recommendations that fell under multiple themes, they were counted under each theme. This can be seen in Figure 4.

As seen in Figure 4, 19 out of 36 papers (52.7\%) provided recommendations in relation to One Health Approach and Collaboration. Environmentalists have come to recognize that the health and state of natural habitat of wildlife is interdependent on health of domestic livestock and humans living in the area (Osofsky et al., 2005). To address the related food safety issues and zoonoses, One Health approach has been proposed. WHO defines it as "an approach to designing and implementing programmes, policies, legislation, and research in which multiple sectors communicate and work together to better achieve public health outcomes" (World Health Organization, 2017, September 21). One Health Approach and Collaboration theme encompasses identified recommendations for planners with respect to health of urban/peri-urban wildlife, pet animals, exotic pets, urban poultry, live animal markets and vector control. Further, collaboration between planning department and public health departments is also central to this theme.

'Urbanization and Sanitation' theme brings together recommendations dealing with land use change and sewer services in relation to zoonoses. 13 out of 36 papers $(36.1 \%)$ provide recommendations that fall under this theme. Rapid urbanization leading to large scale unplanned land use change and lack of efficient sewer facilities are characteristic of many global south countries. Therefore, the recommendations falling under these two areas have been combined under this theme.

'Disaster and Climate Change Preparedness' theme encompasses recommendations dealing with climate change adaptation and flood planning. Further, recommendations dealing with prediction of epidemic pathways are also included under the aegis of disaster preparedness. Only $8.3 \%$ of the papers dealt with this theme. 'Built environment considerations' theme consists of guidelines that introduce zoonotic diseases lens in building design and built environment. 11.1\% of the papers venture into this topic.

It was found that $8.3 \%$ of the papers had 'Equity and Justice' themed recommendations. The suggestions from these papers deal with spatial distribution of risk, surveillance of poorer areas, and recognizing vulnerable groups. Like 'Equity and Justice' and 'Disaster and Climate Preparedness' themes, $8.3 \%$ of papers presented recommendations with reference to 'Urban Forest and Green Space Planning' theme. These recommendations delve into urban park and landscape planning while considering associated risks of zoonoses.

Only $5.5 \%$ of the papers presented recommendations consistent with 'Economic Considerations' theme. These recommendations deal with budgeting for health and handling of economic crisis in relation to zoonoses. 


\subsection{Identified Recommendations}

Based on the review of papers, the recommendations for city planning practitioners and researchers is presented in a thematic manner in this section. These recommendations range from specific stipulations to general guidelines.

\subsubsection{One Health/Collaboration}

i. Domestic and wild animal health should be included in the just conception of health alongside human health (Lysaght, 2017).

ii. Multidisciplinary teams including planners and public health officials should be constituted for addressing and combating urban zoonotic diseases (Ahmed, 2019; Lebov, 2017)

iii. 'Wildlife health impact' assessment should be conducted while allowing new development permits or intensive livestock operations in a new region to reduce vulnerability to emerging zoonoses (Farnese, 2014)

iv. Mapping of wildlife for public should be done in urban areas to reduce human-wildlife conflicts and encounters (Le Lay et al., 2001). This can also reduce disease transmission.

v. Research has shown that personalities of wildlife determine how well they adapt to urban environment. The wildlife should be made to shy away from humans to reduce risk of zoonoses. Therefore, selective culling of bold individuals has been proposed to ensure deliberate selection for shyness while devising Urban Wildlife Management Plans (Honda, et al., 2018).

vi. Exotic pets, petting zoos, and ecotourism are known to increase the incidence of zoonoses. Multidisciplinary teams should be formed to address this challenge. (Chomel et al., 2007)

vii. To effectively manage canine zoonoses like rabies, cities should plan vaccination sites in a manner that ensures optimum spatial coverage and accessibility in cities to ensure efficient use of available resources (Polo et al., 2013).

viii. Canine Faecal Contamination in urban areas can be found in areas like parks and sand pits. There is potential for zoonoses in these cases and needs to be addressed (Renaldi et al., 2006). Hand sanitizing stations for park attendees should be made available to reduce the risk of disease transmission (Rahim et al., 2018).

ix. Knowledge of distribution of pathogens in wildlife hosts in urban areas should be applied to urban maintenance and planning to reduce the impact of zoonoses. For example, prevalence of zoonoses in mice tends to be highest in ports and low-income neighbourhoods (Rothenburger et al., 2017). Further, socio-demographic, physical landscapes and housing characteristics have been closely linked to sightings of rat, a common vector (Walsh, 2014).

x. Live Bird Markets (LBM) play a key role in outbreak of zoonoses like Avian flu while also being socially and economically important spaces. It is important to develop participatory plans involving all stakeholders to prevent, monitor, and manage such disease outbreaks. Participatory process is key as top-down approaches might not work depending on local context (ElMasry et al., 2015). 
xi. To prevent zoonoses from backyard poultry, regulations mandating vaccinations and veterinary care should be adopted by municipalities (Brinkley et al., 2018).

xii. Urban and peri-urban dairy farming locations should be targeted and monitored for zoonoses more frequently as there is risk of leptospirosis among cattle, especially in developing countries with informal milk supply chains (미ala et al.,'2017)

\subsubsection{Urbanization and Sanitation}

i. $\quad$ Rapid land use changes from forested land to urban or agricultural land in peri-urban areas can fragment forests, stress wild animals and increase human- wildlife encounters. This increases chances of zoonoses, especially in areas where population growth is high and environment degradation is rampant (Kilpatrick \& Randolph, 2012; Neiderud, 2015; Whitmee et al., 2015). To anticipate these changes, Millennium Ecosystem Assessment (MEA) framework is recommended for planning as it integrates human wellness while also focusing on ecosystem services (Patz et al. 2004)

ii. In tropical regions where rodent borne leptospirosis occurs, high human activity, low forest cover and lack of natural bodies of water increases the public risk of disease transmission in urban areas. Therefore, cities should acknowledge this growing risk and control rodent population. (Blasdell et al., 2019).

iii. Even environmental restoration and eco-friendly sewage treatment projects where land use is changed can increase risks of vector borne diseases. For example, a newly restored wetland that hosts reed bed for sewage treatment could harbour mosquitoes. Therefore, during the planning process, impact of mosquitoes and its potential to act as disease carrying vectors should be considered (Medlock \& Vaux, 2014).

iv. Rapidly urbanizing regions are at higher risk of zoonoses. For example, higher incidence of hantavirus in China was found to correlate to higher urbanization and economic growth. Therefore, urbanizing cities should focus more on preventing and managing zoonoses (Tian et al., 2018).

v. Unsanitary traditional burial practices (like in Madagascar) and overcrowded urban areas can lead to transmission of zoonoses like pneumonic plague which is spread via rodents and air droplets. To reduce the risk, rodent control and promoting better burial practices should be the top priority of city planning (Rabaan et al., 2019).

vi. Districts where more houses lack sanitation facilities and communities which lack proper urban infrastructures have been associated with higher incidence of Avian Influenza (For example, Vietnam).Thus, such zoonoses outbreaks can be predicted and even avoided by providing better sanitation infrastructure in targeted communities that are deemed to be at risk (Spencer et al., 2020).

\subsubsection{Disaster and Climate Change Preparedness}

i. Climate change adaptation measures can increase risks of zoonoses if not considered as part of the planning process. For example, in Australia, water retention structures built to 
combat the risk of climate change induced drought has increased the risk of dengue. Therefore, it is suggested that zoonoses lens should be integrated into climate change planning (Beebe et al., 2009).

ii. Floods increase the chances of certain zoonoses like leptospirosis in tropical areas. Hence, while approving constructions in areas with high flood risk and planning for floods, zoonoses should be a major consideration in planning approvals (Jagadesh et al., 2019).

iii. Increased minimum temperature during times of flooding is also seen to increase the chances of zoonoses like leptospirosis. Long term effects of climate change on zoonoses should be further investigated and integrated into disaster and climate change planning (Jagadesh et al., 2019).

iv. Large scale computational modelling can be used for predicting the spread of epidemics like SARS through international transportation traffic and census data. Decision making processes and policy interventions can be accelerated at both local and national level without delay (A reaction delay of 1-2 weeks was reported in most countries in the case of SARS) if such models are used (Colizza et al., 2007).

\subsubsection{Built Environment Considerations}

i. Increasing building ventilation rates through methods like natural ventilation at home, classrooms, and offices has been shown to be relatively effective strategy for airborne diseases like SARS in large cities (Gao et al., 2016a; Gao et al., 2016b; Neiderud, 2015). Design guidelines for building ventilation should take this into consideration.

ii. Closeness to public recreational spaces, subway lines, and older housing have been linked to rat sightings (For example, New York). This built environment consideration should be integrated into planning to reduce human-rat encounters (Walsh 2014).

\subsubsection{Equity and Justice Considerations}

i. $\quad$ Poor areas in many cities have bad sanitation facilities and lack access to clean water. Such areas are susceptible to soil transmitted helminths, that are one of the leading causes of physical and mental retardation in the world. In addition to this, rats proliferate in overcrowded locations leading to associated zoonoses. Local knowledge and experience should be integrated into planning for poor neighbourhoods and vector control (especially, rats and mosquitoes) (Neiderud, 2015; Telle \& Paul, 2016).

ii. Planners should prepare contingency plans for sheltering homeless during outbreaks as shelters may have to be closed due to staff shortages. Homeless service providers should be provided with supplies for infection control. Further, spaces for treating and isolating clinically ill individuals needs to be identified in the plan (Leung et al., 2008).

\subsubsection{Economic Considerations}

i. Budgets for vector borne diseases surveillance should be enhanced at all levels of governments as surveillance costs are far lower in comparison with funds needed to 
respond to outbreaks (Vaquez-Prokopec et al., 2010). Civic bodies should be allotted resources to enhance their control measures and surveillance capabilities.

ii. In response to economic crisis at national or local level, budgetary cuts often target healthcare. This has been known to increase infectious disease incidence. For example, in 1990s, budget cuts in New York City led to a shortage of front-line drugs, failure in follow up treatment and screening. Correspondingly, TB incidence rose. In 1990s, a similar increase in incidence of infectious diseases was seen in Mexico in response to cuts. Therefore, cities and states should increase healthcare spending during economic crises to support high risks groups like the elderly, migrants, and homeless (Suhrcke et al., 2011).

\subsubsection{Urban Forest/Green Space Planning}

i. With the incidence of tick-borne infections like Lyme disease increasing, it should be taken into consideration while locating, planning, and designing green spaces. Connectivity of landscape, plot sizes, closeness to agricultural land, and urbanization are some factors that affect the prevalence of Borrelia-infected ticks (Heylen et al., 2019)

ii. To control risk of zoonoses from off leash dog parks, they should be located away from sources of standing water and run off as parasites in dog faeces could pollute water. (Rahim et al., 2018)

iii. Low urban forest cover has been correlated to increased incidence of rodent borne diseases (Blasdell et al., 2019). This should be considered while deciding urban land use, especially in tropical regions.

\section{Discussion}

In this section, an overview of the recommendations is provided. Their applicability to global north and south cities is also discussed.

\subsection{Overview of key findings}

The review has yielded a wide range of guidelines that urban planners can integrate into their practice. One of the key observations is the overlapping and sometimes contradictory stances. When we consider the recommendations under One Health/Collaboration theme, it was clearly noticeable that some recommendations were in favour of treating animals as equals whereas others were more anthropocentric. An article advocated for humane and just treatment of animals (Lysaught, 2017) while the other one called for the culling of undesirable animals (Honda et al., 2018). These stances couldn't be more contrasting. This shows that there are different approaches available for practitioners to address the health of animals in conjunction with human wellbeing.

Role of urbanization and expansion of cities in increasing risks of zoonoses outbreak has been extensively mentioned in the literature (Ahmed et al., 2019; Kilpatrick \& Randolph, 2012; Neiderud, 2015). Literature indicated that these cities are primarily located in tropical and subtropical regions. They are densely populated and situated mostly in Asia and Africa. The 
outbreak of several zoonoses like Ebola, Avian Flu, and SARS have shown us the characteristics of places where outbreak happens. In the provided recommendations, planners have been asked to address some of the key problems that are at the core of these outbreaks. These problems include deforestation, poverty, poor sanitation, and water supply.

The recommendations also highlight the role of exotic pets and live animal markets in increasing the risks of outbreaks. They advocate for multidisciplinary and participatory approaches to address the associated risks (Chomel et al., 2007; ElMasry et al., 2015). In addition to these suggestions, these recommendations have also issued some cautionary statements for planners. This is especially true when it comes to climate change adaptation (Beebe et al., 2009), handling of economic crises (Suhrcke et al., 2011), and green space planning (Heylen et al., 2019). These recommendations suggest that when zoonotic diseases lens isn't applied in these scenarios, the planned measures might end up exacerbating risks. To manage the risk of zoonoses, papers also argue for infectious diseases considerations to be incorporated into building design.

\subsection{Applicability of Recommendations}

Most of these recommendations and their underlying principles can be adopted by city planners across the world. However, geographical location and availability of resources also play a major role in their ability and willingness to adopt these recommendations.

Higher mammalian species diversity in the tropics increases the risk of disease emergence in the region (Allen et al., 2017; Murray \& Daszak, 2013). Therefore, when compared to the tropics, developed countries in temperate and polar areas are not as likely to be source regions for novel zoonoses. Further, the developed countries have better sanitation infrastructure, healthcare, enforcement of various safety codes, and planned urban expansion. This can also reduce chances of zoonoses outbreak. However, climate change can alter the geography of diseases and there are risks associated with zoonoses and disease vectors originating from tropics and subtropics (Lafferty, 2009; Naicker, 2011).

Cities in developed nations are better equipped to implement most of the identified recommendations in a comprehensive manner because of the good service delivery infrastructure and governance systems in place. However, many global south cities lack wider coverage when it comes to various service delivery and infrastructure. This does not only act as the impediment for incorporating EZD lens in planning, but it also facilitates and creates conducive environments for zoonoses outbreak. This means that EZD is one more reason in the list of many for prioritizing infrastructure, enforcement of safety codes, service delivery, unchecked urbanization, and environmental protection in developing and underdeveloped nations. The recommendations addressing living conditions, rapid urbanization, and deforestation are very relevant in the case of poorer nations. Without these crucial improvements it would be challenging to implement other suggestions.

The identified suggestions make a case for enhanced rules, legislation and enforcement in any local and regional jurisdiction. However, a challenge when it comes to highly contagious EZD like COVID-19 is that they transcend local and regional boundaries. Geopolitical dynamics and 
priorities in multi-national governance settings that play an essential role in policy response and disease transmission have not been considered a factor in the identified recommendations.

\subsection{Recommendations for Research}

Since the research at the interface of planning and EZD is relatively new, more initiative from researchers is required for mainstreaming zoonotic infectious diseases considerations in urban planning. Research should be geared towards modifying existing planning frameworks to accommodate zoonoses. Increasing city's resilience to outbreaks of zoonoses should also be prioritized in research. This is especially important as climate change could alter the geography of some zoonoses (Lafferty, 2009; Séguin et al., 2008). Further, barriers to mainstreaming EZD considerations in different regional, social, and economic contexts requires further investigation.

While connectivity in terms of travel and communication has benefitted many cities and is well documented in research, research on prevention of EZD in globalized cities is only evolving. Therefore, the role and implications of globalization requires renewed attention among researchers.

\subsection{Recommendations for Planning Practice}

This scoping review provides several examples of relationships between planning and EZD. This knowledge needs to be integrated into practice. All the recommendations identified, might not suit the local context where practitioners live and work. Therefore, effort should be made to incorporate the underlying principles of the recommendations like One Health and inclusion of the vulnerable population in the planning processes.

The incorporation of these principles into urban planning practice will not look the same in different jurisdictions around the world as urban governance models vary significantly. For example, India and Hungary adhere to a more centralised planning framework with relatively lower independence for local governments (Ahluwalia, 2019; OECD, 2019). Further, municipalities lack capacity to carry out a wide range of tasks. Contrastingly, in OECD countries like the United States, Germany, Spain and Canada, cities wield greater independence in policy making, financing, and land use planning (OECD, 2019). This variation in governance structure means that the task of mainstreaming EZD must be taken at different levels of government depending on their current framework.

Central and regional governments in countries that follow a five-year planning cycle (e.g., China, South Korea and India) should consider embedding these identified recommendations regarding EZD in their national level urban development programs and environmental legislation. In the case of countries like Canada and the United States, actors at different levels of government have greater capacity to incorporate EZD considerations (Slack, 2017). Municipalities can incorporate EZD in their master and official plans, zoning bylaws and development application processes, while provincial and federal governments can provide special grants to municipalities to incentivize these tasks. Provincial and federal governments can go further and incorporate EZD considerations into their planning legislation and environmental impact assessment acts and 
policies. However, the incorporation process would require further deliberation among the planning practitioners, politicians and public living within a jurisdiction.

\subsection{Strengths and limitations of this scoping review}

This scoping review was conducted in a transparent and rigorous manner. To make sure that different kinds of papers are obtained, web search was conducted in addition to searching three databases. RefWorks software employed in this review made sure that all studies were reviewed and accounted for.

However, this scoping review is only capable of providing an overview of recommendations for planners and it is not exhaustive. Since only three journal databases were searched for articles, there is room for a detailed systematic review. Further, only one reviewer was involved in conducting this review and therefore this review reflects the judgement of one person. Having multiple reviewers might have resulted in a review that looks different.

\section{Conclusion}

Research literature examining the relationship between urban planning and emerging zoonoses is expanding over time. However, more region and context specific studies are required to integrate and operationalize this knowledge into planning practice. Reintegration of infectious diseases in urban planning practice would require conscious efforts of researchers and practitioners over a period. However, the onset of COVID-19 should be seen as an opportunity to fast track the integration of emerging zoonoses. The ideas and guidelines provided in this review can be a starting point for this endeavour.

As EZD risks are very globalized, the developed world has vested interest in the betterment of conditions in global south cities to reduce exposure to these risks. The wealthier countries across the world would need to make concerted efforts to improve the living conditions and incentivize the integration of EZD considerations in economically weaker regions of the world. 


\section{References}

Ackerknecht, E. H., \& Haushofer, L. (2016). A short history of medicine JHU Press.

Ahluwalia, I. J. (2019). Urban governance in India. Journal of Urban Affairs, 41(1), 83-102.

Ahmed, S., Dávila, J. D., Allen, A., Haklay, M. (., Tacoli, C., \& Fèvre, E. M. (2019). Does urbanization make emergence of zoonosis more likely? evidence, myths and gaps. Environment \& Urbanization, 31(2), 443-460. doi:10.1177/0956247819866124

Allen, T., Murray, K. A., Zambrana-Torrelio, C., Morse, S. S., Rondinini, C., Di Marco, M., ... \& Daszak, P. (2017). Global hotspots and correlates of emerging zoonotic diseases. Nature communications, 8(1), 1-10.

Bardosh, K. (2016). One health (1st ed.). London: Routledge Ltd. doi:10.4324/9781315659749 Retrieved from https:/www.taylorfrancis.com/books/e/9781315659749

Beebe, N. W., Cooper, R. D., Mottram, P., \& Sweeney, A. W. (2009). Australia's dengue risk driven by human adaptation to climate change doi:10.1371/journal.pntd.0000429

Blasdell, K. R., Morand, S., Perera, D., \& Firth, C. (2019). Association of rodent-borne leptospira spp. with urban environments in malaysian borneo doi:10.1371/journal.pntd.0007141

Brinkley, C., Kingsley, J. S., \& Mench, J. (2018). A method for guarding animal welfare and public health: Tracking the rise of backyard poultry ordinances. Journal of Community Health, 43(4), 639-646. doi:10.1007/s10900-017-0462-0

Chomel, B. B., Belotto, A., \& Meslin, F. (2007). Wildlife, exotic pets, and emerging zoonoses. Emerging Infectious Diseases, 13(1), 6-11. doi:10.3201/eid1301.060480

Ciecieznski, N. J. (2013). The stench of disease: public health and the environment in latemedieval English towns and cities. Health, Culture and Society, 4(1), 91-104.

Colizza, V., Barrat, A., Barthélemy, M., \& Vespignani, A. (2007). Predictability and epidemic pathways in global outbreaks of infectious diseases: The SARS case study. BMC Medicine, 5, 34. doi:10.1186/1741-7015-5-34

Coronavirus outbreak 'greatest test since WW2'. (2020, April 01). BBC News. Retrieved from https://www.bbc.com/news/world-52114829

De Moncan, P., \& Heurteux, C. (2002). Le Paris d'Haussmann. Ed. du Mécène.

Duhl, L. J., \& Sanchez, A. K. (1999). Healthy cities and the city planning process: a background document on links between health and urban planning (No. EUR/ICP/CHDV 030403 ). Copenhagen: WHO Regional Office for Europe.

ElMasry, I., Elshiekh, H., Abdlenabi, A., Saad, A., Arafa, A., Fasina, F. O., . . Jobre, Y. M. (2017). Avian influenza H5N1 surveillance and its dynamics in poultry in live bird markets, egypt doi:10.1111/tbed.12440

Ewert, U. C. (2007). Water, public hygiene and fire control in medieval towns: facing collective goods problems while ensuring the quality of life. Historical Social Research/Historische Sozialforschung, 222-251. 
Oaks Jr, S. C., Shope, R. E., \& Lederberg, J. (Eds.). (1992). Emerging infections: microbial threats to health in the United States. National Academies Press.

Gao, X., Wei, J., Cowling, B. J., \& Li, Y. (2016a). Potential impact of a ventilation intervention for influenza in the context of a dense indoor contact network in hong kong. The Science of the Total Environment, 569-570, 373-381. doi:10.1016/j.scitotenv.2016.06.179

Gao, X., Wei, J., Lei, H., Xu, P., Cowling, B. J., \& Li, Y. (2016b). Building ventilation as an effective disease intervention strategy in a dense indoor contact network in an ideal city. PloS One, 11(9), e0162481. doi:10.1371/journal.pone.0162481

Garcia, Rita de Cassia Maria, Calderón, N., \& Ferreira, F. (2012). [Consolidation of international guidelines for the management of canine populations in urban areas and proposal of performance indicators]. Revista Panamericana De Salud Publica = Pan American Journal of Public Health, 32(2), 140-144. doi:10.1590/s1020-49892012000800008

Gottfried, R. S. (2010). Black death. Simon and Schuster.

Heylen, D., Lasters, R., Adriaensen, F., Fonville, M., Sprong, H., \& Matthysen, E. (2019). Ticks and tick-borne diseases in the city: Role of landscape connectivity and green space characteristics in a metropolitan area doi:10.1016/j.scitotenv.2019.03.235

Honda, T., Iijima, H., Tsuboi, J., \& Uchida, K. (2018). A review of urban wildlife management from the animal personality perspective: The case of urban deer doi:10.1016/j.scitotenv.2018.06.335

Jagadesh, S., Combe, M., Couppié, P., Le Turnier, P., Epelboin, L., Nacher, M., \& Gozlan, R. E. (2019). Emerging human infectious diseases of aquatic origin: A comparative biogeographic approach using bayesian spatial modelling. International Journal of Health Geographics, 18(1), 23. doi:10.1186/s12942-019-0188-6

Jonathan A. Patz, Peter Daszak, Gary M. Tabor, A. Alonso Aguirre, Mary Pearl, Jon Epstein, . . . Members of the Working Group on Land Use Change and Disease Emergence. (2004). Unhealthy landscapes: Policy recommendations on land use change and infectious disease emergence. Environmental Health Perspectives, 112(10), 1092-1098. doi:10.1289/ehp.6877

Kara, B. (2019). The impact of globalization on cities. Journal of Contemporary Urban Affairs, 3(2), 108-113. doi:10.25034/ijcua.2018.4707

Kilpatrick, A. M., Prof, \& Randolph, S. E., Prof. (2012). Drivers, dynamics, and control of emerging vector-borne zoonotic diseases. Lancet, The, 380(9857), 1946-1955. doi:10.1016/S0140-6736(12)61151-9

Kochtitzky, C. S., Frumkin, H., Rodriguez, R., Dannenberg, A. L., Rayman, J., Rose, K., ... Centers for Disease Control and Prevention. (2006, December 22). Urban planning and public health at CDC. Retrieved from https:/www.ncbi.nlm.nih.gov/pubmed/17183243

Lafferty, K. D. (2009). The ecology of climate change and infectious diseases. Ecology, 90(4), 888-900. 
Le Lay, G., Clergeau, P., \& Hubert-Moy, L. (2001). Computerized map of risk to manage wildlife species in urban areas. Environmental Management, 27(3), 451-461. doi:10.1007/s002670010161

Leung, C. S., Ho, M. M., Kiss, A., Gundlapalli, A. V., \& Hwang, S. W. (2008). Homelessness and the response to emerging infectious disease outbreaks: Lessons from SARS. Journal of Urban Health: Bulletin of the New York Academy of Medicine, 85(3), 402-410. doi:10.1007/s11524008-9270-2

Lysaght, T., Capps, B., Bailey, M., Bickford, D., Coker, R., Lederman, Z., . . Tambyah, P. A. (2017). Justice is the missing link in one health: Results of a mixed methods study in an urban city state. PloS One, 12(1), e0170967. doi:10.1371/journal.pone.0170967

McKeown, T. (1971). A historical appraisal of the medical task. Medical history and medical care, 29-50.

Medlock, J. M., \& Vaux, A. G. C. (2014). Colonization of a newly constructed urban wetland by mosquitoes in england: Implications for nuisance and vector species. Journal of Vector Ecology: Journal of the Society for Vector Ecology, 39(2), 249-260. doi:10.1111/jvec.12099

Morse, S. S., Mazet, J. A., Woolhouse, M., Parrish, C. R., Carroll, D., Karesh, W. B., ... \& Daszak, P. (2012). Prediction and prevention of the next pandemic zoonosis. The Lancet, 380(9857), 1956-1965.

Murray, K. A., \& Daszak, P. (2013). Human ecology in pathogenic landscapes: two hypotheses on how land use change drives viral emergence. Current opinion in virology, 3(1), 79-83.

Naicker, P. R. (2011). The impact of climate change and other factors on zoonotic diseases. Archives of Clinical Microbiology, 2(2).

Narayana, M. R. (2010). Impact of economic globalization on urbanization: A comparative analysis of indian and select global experiences. India Quarterly, 66(1), 91-116. doi:10.1177/097492841006600106

Neiderud, C. (2015). How urbanization affects the epidemiology of emerging infectious diseases. Infection Ecology \& Epidemiology, 5, 27060. doi:10.3402/iee.v5.27060

OECD. (2019). Making Decentralisation Work: A Handbook for Policy-Makers.

Osofsky, S. A., Cleaveland, S., Karesh, W. B., Kock, M. D., Nyhus, P. J., Starr, L., \& Yang, A. (Eds.). (2005). Conservation and Development Interventions at the Wildlife/Livestock Interface: Implications for Wildlife, Livestock and Human Health. IUCN, Gland, Switzerland and Cambridge, UK.

Pijnenburg, M. A., \& Leget, C. (2007). Who wants to live forever? three arguments against extending the human lifespan. Journal of Medical Ethics, 33(10), 585-587.

Polo, G., Acosta, C. M., \& Dias, R. A. (2013). Spatial accessibility to vaccination sites in a campaign against rabies in são paulo city, brazil. Preventive Veterinary Medicine, 111(1-2), 10-16. doi:10.1016/j.prevetmed.2013.03.010

Rabaan, A. A., Al-Ahmed, S. H., Alsuliman, S. A., Aldrazi, F. A., Alfouzan, W. A., \& Haque, S. (2019). The rise of pneumonic plague in madagascar: Current plague outbreak breaks usual 
seasonal mould. Journal of Medical Microbiology, 68(3), 292-302. doi:10.1099/jmm.0.000915

Rahim, T., Barrios, P. R., McKee, G., McLaws, M., \& Kosatsky, T. (2018). Public health considerations associated with the location and operation of off-leash dog parks. Journal of Community Health, 43(2), 433-440. doi:10.1007/s10900-017-0428-2

Rajala, E. L., Sattorov, N., Boqvist, S., \& Magnusson, U. (2017). Bovine leptospirosis in urban and peri-urban dairy farming in low-income countries: A "one health" issue? Acta Veterinaria Scandinavica, 59(1), 83. doi:10.1186/s13028-017-0352-6

Rinaldi, L., Biggeri, A., Carbone, S., Musella, V., Catelan, D., Veneziano, V., \& Cringoli, G. (2006). Canine faecal contamination and parasitic risk in the city of naples (southern italy). BMC Veterinary Research, 2, 29. doi:10.1186/1746-6148-2-29

Rock, M. J. (2017). Who or what is 'the public'in critical public health? Reflections on posthumanism and anthropological engagements with One Health. Critical Public Health, 27(3), 314-324.

Rothenburger, J. L., Himsworth, C. H., Nemeth, N. M., Pearl, D. L., \& Jardine, C. M. (2017). Environmental factors and zoonotic pathogen ecology in urban exploiter species. EcoHealth, 14(3), 630-641. doi:10.1007/s10393-017-1258-5

Saldanha-Elias, A. M., Silva, M. A., Silva, V. O., Amorim, S. L. A., Coutinho, A. R., Santos, H. A., ... \& Geiger, S. M. (2019). Prevalence of endoparasites in urban stray dogs from Brazil diagnosed with Leishmania, with potential for human zoonoses. Acta parasitologica, 64(2), 352-359.

Séguin, J., Berry, P., Bouchet, V., Clarke, K. L., Furgal, C., Environmental, I., \& MacIver, D. (2008). Human health in a changing climate: a Canadian assessment of vulnerabilities and adaptive capacity. Human health in a changing climate, 1 .

Slack, E. (2017). How Much Local Fiscal Autonomy Do Cities Have? A Comparison of Eight Cities around the World, IMFG Perspectives 19, University of Toronto.

Spencer, J. H., Finucane, M. L., Fox, J. M., Saksena, S., \& Sultana, N. (2020). Emerging infectious disease, the household built environment characteristics, and urban planning: Evidence on avian influenza in vietnam doi:10.1016/j.landurbplan.2019.103681

Suhrcke, M., Stuckler, D., Suk, J. E., Desai, M., Senek, M., McKee, M., . . Semenza, J. C. (2011). The impact of economic crises on communicable disease transmission and control: A systematic review of the evidence. PloS One, 6(6), e20724. doi:10.1371/journal.pone.0020724

Taylor, L. H., Latham, S. M., \& Woolhouse, M. E. (2001). Risk factors for human disease emergence. Philosophical Transactions of the Royal Society of London.Series B: Biological Sciences, 356(1411), 983-989.

Telle, O., \& Paul, R. (2016). Emerging Diseases and Socio-spatial Disparities. Economic \& Political Weekly, 51(13), 23. 
Tian, H., Hu, S., Cazelles, B., Chowell, G., Gao, L., Laine, M., ... \& Tong, X. (2018). Urbanization prolongs hantavirus epidemics in cities. Proceedings of the National Academy of Sciences, 115(18), 4707-4712.

van Doorn, H. R. (2014). Emerging infectious diseases. Medicine, 42(1), 60-63.

Vazquez-Prokopec, G. M., Chaves, L. F., Ritchie, S. A., Davis, J., \& Kitron, U. (2010). Unforeseen costs of cutting mosquito surveillance budgets. PLoS Neglected Tropical Diseases, 4(10), e858. doi:10.1371/journal.pntd.0000858

Walsh, M. G. (2014). Rat sightings in new york city are associated with neighborhood sociodemographics, housing characteristics, and proximity to open public space doi: $10.7717 /$ peerj.533

Weiss, R. A. (2001). The leeuwenhoek lecture 2001. animal origins of human infectious disease. Philosophical Transactions of the Royal Society of London.Series B: Biological Sciences, 356(1410), 957-977.

Whitmee, S., Haines, A., Beyrer, C., Boltz, F., Capon, A. G., De Souza Dias, B. F., . . Yach, D. (2015). Safeguarding human health in the anthropocene epoch: Report of the rockefeller foundation-lancet commission on planetary health doi:10.1016/S0140-6736(15)60901-1

World Economic Forum. (2020). The Global Risks Report 2020.

World Health Organization. (2017, September 21). One Health. Retrieved May 07, 2020, from https://www.who.int/news-room/q-a-detail/one-health 